\title{
Motivation as a factor affecting the efficiency of cognitive processes in elderly patients with hypertension
}

\author{
Yury P. Zinchenko ${ }^{a}$, Elena I. Pervichko ${ }^{a}$, Olga D. Ostroumova ${ }^{b}$ \\ ${ }^{a}$ Lomonosov Moscow State University, Moscow, Russia \\ ${ }^{b}$ Moscow State University of Medicine and Dentistry, Moscow, Russia
}

\begin{abstract}
The main purpose of the present study was to assess the role of motivation in the effective cognitive activity of elderly hypertension (HTN) patients provided with antihypertensive treatment; 25 patients with HTN took part in the study, stage 1-2; their mean age was 67.6 \pm 6.1 . The psychological examination program embraced a quantitative measurement of intelligence quotient (IQ) with the Wechsler Adult Intelligence Scale, and an investigation into the qualitative features of their cognitive processes, applying a pathopsychological study procedure (Zeigarnik, 1962,1972) and the principles of psychological syndrome analysis (Vygotsky-Luria-Zeigarnik school). The results showed that within the psychological syndrome structure of cognitive disorders in HTN patients, the leading part is played by two syndrome-generating factors: a neurodynamic factor and a motivational factor. The patients with reduced motivation would achieve poor general test results, if compared with the group of highly motivated participants. A correlation analysis of the data revealed the interconnection between frequency disturbances in motivation and the frequency in occurrence of various signs of cognitive decline, such as low efficiency in memorization and delayed recall, as well as lower IQ test results. The data provide a strong argument to support the hypothesis that motivation is of particular importance as a factor in the generation of cognitive disorders in HTN patients.
\end{abstract}

Keywords: hypertension at work, essential hypertension, mental stress, state anxiety, psychophysiological mechanisms, aspiration level, emotion regulation, repression of emotions.

\section{Introduction}

A theory only thrives when it evolves.

April 4th, 2013 marked the 80th birthday of the eminent Russian psychologist Oleg K. Tikhomirov. A brilliant disciple of A.R. Luria, A.N. Leontyev, B.V. Zeigarnik, and P.Ya. Galperin, he formulated the Personal Meanings Theory of thinking, a striking conception which continues to evolve today. His research record sustains and considerably develops the theses of the activity approach in psychological studies. Like B.V. Zeigarnik, he regarded thinking as a distinctive cognitive activity, 
which was fundamentally intertwined with motivation, to heighten partiality and a poly-motivated character of human thinking (Tikhomirov, 1984; Vasilyev, Popluzhny, Tikhomirov, 1980).

The correlation of personal and 'essentially intellectual processes' in problem solving lies at the core of faulty reasoning, which was fruitfully explored by O.K. Tikhomirov from the viewpoint of general psychology. The issue is of current importance for clinical psychology as well. The identification of syndrome-generating factors that call elicit cognitive disturbances dictates treatment strategies, which may be different for each patient.

Hypertension (HTN) is the most frequently occurring complaint among the elderly (60-74 years) and senile (75-89 years). The number of patients suffering from HTN in these age groups approaches 50-60\% (Souetre, Qing, Vigoureux, 1995; Kearney, 2005).

HTN may be related to a higher risk of cerebrovascular illnesses, cardiac and renal failure or the development of ischemic heart disease. The brain is the main target in patients with HTN. Continual HTN may result in the morphologic restructuring of blood vessels and the microcirculatory blood stream. In the long run, it may lead to various brain dysfunctions that fall within a vast range of states, from clinically untraced symptoms to severe vascular dementia (Kilander, et al., 1998; Carlson \& Wyss, 2011; Cohen, 2011). The latter adversely affects the quality of life of the patient and his/her treatment compliance, and brings on higher mortality (Hamer, 2010; Krzesinski \& Leeman, 2011; et al.).

Vascular (or subcortical) dementia is most frequent among patients with HTN. Data from clinical studies reveal that this type of dementia is characterized by memory impairment, although it only applies to short-term memory disfunctions , without clinically manifesting signs of amnesia. It brings about difficulty in the retention of words, or visual information, and handicaps the acquisition of new motor skills. Voluntary and involuntary memorization may be both affected, although involuntary memorization appears more vulnerable (Graf \& Mandler, 1984). It basically affects active recall, as simple recognition of the material is preserved almost intact. Stimulation from the outside, e.g. some help in memorizing, semantic linkage in data processing, or repeated presentations of the material may help encourage memorization (Nekrasova, 1987; Huppert \& Kopellman, 1989; Korsakova \& Varako, 2005).

Russian studies in neuropsychology reveal that patients with HTN face certain difficulties in terms of intellectual activity. Almost every patient exhibits malfunctions in programming and control, inadequacy in simultaneous syntheses, and a lowering of the level of generalization in the problem solving . All of these symptoms are described by classical neuropsychology in terms of the dysfunction of the frontal lobes (Luria, 1980; Homskaya, 1987; Korsakova \& Moskovichute, 2003). There are other symptoms within the syndrome structure of dysfunctions of mental activity that are caused by HTN: reduction in energy and a neurodynamic provision of mental activity, which manifests itself in lability, rapid exhaustion, and attention disorders, with memory traces apparently inhibited by interfering effects (Nekrasova, 1987; Korsakova \& Varako, 2005).

Cognitive dysfunctions in HTN patients are characterized by a gradual intensification in symptomatology, shaping an 'undulating' course, marked by periods 
of compensation and decompensation. The states of dementia that are caused by HTN have been thoroughly explored by contemporary science, but the states preceding dementia still await further investigation. Such an investigation should be conducted in several ways: the intensity of cognitive dysfunctions should be traced and measured, as well as the contribution of the brain's emotional and motivational factors to the cognitive disorders.

\section{Research objectives and methods}

The main purpose of the present study was to assess the role of motivation as a factor in measuring the effective cognitive activity of elderly HTN patients which are provided with antihypertensive treatment.

Research design, analysis and data interpretation were carried out in accordance with the fundamentals of L.S. Vygotsky's cultural-historical concept of mental development, A.N. Leontev's theory of activity, and Vygotsky/Luria/ Zeigarnik's conception of psychological syndrome analysis (Zeigarnik, 1972; Luria, 1980; Leont'ev, 1987; Vygotsky, 1993).

The study was conducted using 25 patients with HTN ( 7 males and 18 females), stage 1-2; the mean age was 67.6 \pm 6.1 . Mean HTN duration had approached 11.7 \pm 3.7 years. They had not been provided with antihypertensive treatment for at least two weeks before the experiment. The participants had been selected in accordance with the following criteria: their anamnesis should record no strokes or cardiac infarctions, no apparent clinical respiratory, gastrointestinal or kidney diseases, hematological disorder, severe endocrine disruption, neurological complications or mental disorders. All of the patients had to have completed secondary education or higher.

The medical work-up provided a routine blood pressure (BP) measurement, an assessment of whether or not the subjects were 'fit' or 'unfit', ambulatory blood pressure monitoring (ABPM), and an inquiry into the subjects' medical histories. They were all prescribed antihypertensive therapy with a fixed dose combination (amlodipine $5 \mathrm{mg} /$ lisinopril $10 \mathrm{mg}$ ) for 24 weeks, with dose titration if necessary. At the end of the treatment, medical and psychological testing was conducted again.

The schedule of the psychological study included an IQ test; the Wechsler Adult Intelligence Scale was used (Wechsler, 1955; Filimonenko \& Timofeev, 2001). An investigation was made into qualitative features of cognitive processes, which featured a pathopsychological examination (Zeigarnik, 1972); the principles of psychological syndrome analysis were employed (Vygotsky- Luria- Zeigarnik school).

An experimental pathopsychological study of intellectual activity, conducted on the basis of a B.V. Zeigarnic analysis of pathology of thinking, was used to assess the level of generalization (i.e. the patient's ability to accomplish intricate mental operations and to deal with complex concepts in the course of the experiment), as well as the qualitative features of thinking: the ability to maintain focus and follow a single strategy in problem solving, to control the process, and to suggest the most appropriate solutions for generalizations in the course of the experiment. This avoided so called 'latent features' (if capable of high level generalizations). In 
the course of the experiment the following psychological methods were employed: the Method of exceptions (objects exceptions), "The understanding of metaphorical meaning", the "establishment of the successions of events", and the pictograms method (Zeigarnik, 1965, 1972; Rubinstein, 1970). Negative symptoms surfaced when the level of generalization was lowered and the process of generalization was distorted (when a patient would resort to 'latent featuring'), as well as the multilevel diversity of thinking (the inability to follow a single strategy in problem solving).

Memory research embraced immediate audio-verbal and visual memorization, and mediated memorization, which was introduced by the pictograms method. Audio-verbal memorization testing was conducted in two steps: " 10 words to memorize" and "memorizing two groups, each consisting of three words" (Zeigarnik, 1965; Kiyaschenko, 1973). We were to assess the general productivity of immediate and delayed recall, and the effect of homogeneous and heterogeneous interference. Visual memory testing was carried out by the " 5 figures" method (a patient was to copy five outlines with indefinite shapes to memorize and subsequently reproduce them in the course of testing; Kiyaschenko, 1973). Participants would reproduce the outlines both immediately and after a delay (after heterogeneous interference). Negative symptoms might be manifested in the decrease of memory amount, the de-sequencing of reproduced stimuli, the pathological effect of homogeneous and heterogeneous interference, confabulations, contaminations, and cases of paraphasia.

To study voluntary attention and sensomotor reaction rates, we employed Schulte Tables (Rubinstein, 1970). A succession of five tables was introduced. The patients were instructed to get through the whole list as quickly as possible while avoiding errors. We were to assess a slowdown in activity and the instability of production, which may account for difficulties in concentration and limited attention spans.

The statistical processing of the data was conducted with the implication of various methods: a calculation of mean values and standard deviation, frequency analysis, certainty computation for distinctions between samples based on indicators of the probability of distinctions between indicators (Mann-Whitney U-test), and the revelation of correlations among investigated features in groups of participants, employing the method of calculating Spearman's rank correlation coefficient $\left(r_{s}\right)$.

\section{Results and their discussion}

\section{Results of IQ testing (Wechsler Adult Intelligence Scale)}

Intelligence testing conducted using the Wechsler Adult Intelligence Scale (WAIS) revealed that IQ indices for all HTN patients that were selected for the experiment ranged between 96 and 124; 56\% of participants obtained scores reflecting an "Average intelligence" (according to Wechsler's classification labels, they correspond to IQs of between 90 and 109). An additional 28\% of participants possessed a "High Average" IQ (110-119), and 16\% were classified as "Well above Average" (120-129) (Wechsler, 1955; Filimonenko \& Timofeev, 2001). 
The dynamic analysis gave evidence of negligible growth in scores against the background of pressure leveling-off during 24 weeks of antihypertensive therapy. There was no evidence of reliable distinction between the mean values of verbal and non-verbal intelligence, both before and after the treatment $(p>0.05)$, although $36 \%$ of the participants slightly excelled in non-verbal performance, if we compare it with their verbal scores. These results are presented in Table 1.

Table 1. Average intelligence quotient values in HTN patients before and after the treatment (points)

\begin{tabular}{|c|c|c|}
\hline Parameters of intelligence quotient & $\begin{array}{l}\text { Survey } 1, n=25 \\
\quad(M e \pm S D)\end{array}$ & $\begin{array}{l}\text { Survey } 2, n=25 \\
\quad(M e \pm S D)\end{array}$ \\
\hline Full-Scale IQ (FSIQ) & $106.16 \pm 6.21$ & $108.32 \pm 7.48$ \\
\hline Verbal IQ (VIQ) & $103.58 \pm 7.35$ & $106.579 \pm 7.07$ \\
\hline Non-Verbal Performance IQ (PIQ) & $108.68 \pm 4.67$ & $109.684 \pm 8.52$ \\
\hline
\end{tabular}

Note. $\mathrm{Me}-$ mean; $\mathrm{SD}$ - standard deviation. There are no significant differences between the groups in terms of IQ.

To follow Wechsler in his interpretation of non-verbal intelligence as a storage of individual life experience (Wechsler, 1955), we may come to the conclusion that in the course of problem solving, participants of this particular sample are prone to resort to cut-and-polished patterns. More challenging tasks that encourage new solutions, and thus place extra demand on them in terms of mental activity were performed with less enthusiasm and productivity.

To sum it up, regarding the results of the Wechsler Intelligence Scale, we may assert that the elderly HTN patients selected for the experiment revealed IQ indices within the range of normal age-specific values, which tend to grow on the top of administered anti-hypertensive therapy. Moreover, the obtained results (according to which the values of non-verbal intelligence outscore those of verbal intelligence) may come as indirect evidence of motivation being a significant factor for IQ testing among the surveyed HTN patients.

\section{Pathopsychological analysis of cognitive functions of HTN patients}

The assessment of cognitive functions followed the procedure of a pathopsychological study (Zeigarnik, 1965, 1972).

A statistical analysis of the whole set of obtained data showed that more often than not, patients revealed disturbances in their memory and thinking. Memory disturbances were displayed by 21 participants $(84 \%)$. Twenty-four weeks of treatment did not bring a reliable improvement; on the contrary, we may assert a certain change for the worse in generalized values. Re-examination revealed memory impairment for 22 patients (88\%). Disturbances in thinking of various types had been initially detected for 20 patients (80\%). After medication therapy, disturbances of intellectual activity were displayed by 13 patients (52\%). The indicated improvement is highly significant $(\mathrm{p}<0.001)$. Attention tests revealed that patents suffered from unstable concentration and that their attention was rapidly exhausted, both 
before and after the treatment. Before the experiment, 17 (68\%) patients showed signs of impaired attention; re-examination revealed 15 patients $(60 \%)$. These data are presented in Table 2 .

Table 2. Data of cognitive disorders before and after the antihypertensive therapy (percentage of patients that failed to accomplish tests)

\begin{tabular}{ccc}
\hline \multirow{2}{*}{ Parameters } & Survey 1, $\mathbf{n}=\mathbf{2 5}$ & Survey 2, $\mathbf{n = 2 5}$ \\
\cline { 2 - 3 } & Absolute Value (\%) & Absolute Value (\%) \\
\hline Thinking disorders & $20(80 \%)$ & $13^{\star}(52 \%)$ \\
Memory disorders & $21(84 \%)$ & $22(88 \%)$ \\
Attention disorders & $17(68 \%)$ & $15(60 \%)$ \\
\hline
\end{tabular}

Note. ${ }^{*}$ Differences in values before and after the treatment are significant $(\mathrm{p}<0.001)$. Now we may proceed to details.

The study of thinking brought to light apparent disturbances of intellectual activity in the selected elderly HTN patients. At that we mean the diagnostics of peculiar qualitative disturbances, which cannot be described just in terms of revealed/unrevealed cognitive decline.

Table 3. Data of parameters of disturbances in thinking before and after the antihypertensive therapy (percentage of patients that failed to accomplish tests)

\begin{tabular}{lcc}
\hline \multirow{2}{*}{ Disturbances in thinking } & Survey 1, $\mathbf{n = 2 5}$ & Survey 2, $\mathbf{n = 2 5}$ \\
\cline { 2 - 3 } & Absolute Value (\%) & Absolute Value (\%) \\
\hline Impulsive answers & $20(80 \%)$ & $13(52 \%)^{*}$ \\
$\begin{array}{l}\text { Disturbances of strategic decision making in } \\
\text { problem solving }\end{array}$ & $16(64 \%)$ & $13(52 \%)$ \\
Sluggishness of thinking & $4(20 \%)$ & $4(20 \%)$ \\
Lability of thinking & $21(80 \%)$ & $18(72 \%)$ \\
Specifically situational mode of problem solving & $14(56 \%)$ & $15(60 \%)$ \\
Distortion of the process of generalization & $21(84 \%)$ & $14(56 \%)^{*}$ \\
Multilevel diversity of thinking & $21(84 \%)$ & $15(60 \%)^{*}$ \\
\hline
\end{tabular}

Note. ${ }^{\star}$ Differences in values before and after the treatment are significant $(\mathrm{p}<0.05)$.

To begin with, most of the patients ( $80 \%$ before the treatment and $52 \%$ after the medication therapy), apart from likely changes in way of thinking, would display disturbances in the programming, regulation, and control of their thinking. This manifests itself in disturbances that affected strategic decision-making in problem solving, and in the impulsive character of most answers. Obtained data bring forward the evidence of dysfunction of frontal lobes, according to the interpretation 
in the framework of neuropsychological syndrome analysis. However, a pathopsychological interpretation of the data may suggest a hypothesis of motivational background for the described disturbances. At the same time, it is noteworthy that thinking processes display the most apparent reduction of the negative symptoms after therapy (Tables 2 and 3 ).

In the second place, there were a large number of answers shaped in a specifically situational mode, both in the objects exceptions test and in the pictograms method (see Table 3) For all cases within the present study, specifically situational modes of answers (establishment of concrete connections between objects) would coincide either with activity drops caused by organic reasons, or with the actualization of an aberrant or conflicting motivation of the patient. The fact is verified by the correlation analysis data (see Appendix, Table 1) and the qualitative analysis of the results. When problem solving was not marked by the actualization of a conflicting motivation, all the patients revealed the capacity to operate with complex notions, to distinguish essential features of items and phenomena, to establish logical links and relations between them. Interpretation of the data in terms of psychological syndrome analysis and the pathology of thinking theory advanced by B.V. Zeigarnik bring us to conclude that the HTN patients selected for our study reveal no lowering of the level of generalization. Their level of generalizations accords with the age norm.

Ultimately, a fact emerges that is especially noteworthy in the context of our research: the distortion of the process of generalization and multilevel diversity of thinking appear to be most frequent within the study of disturbances in thinking (see Table 3). Studies on thinking accomplished by B.V. Zeigarnik and her progeny followers have conclusively verified the fact that such peculiarities of intellectual activity represent specific qualitative rather than quantitative features (a decline of intellect). The former are caused by a disruption in the process of goal setting when affected by the actualization of an aberrant or conflicting motivation during the course of an experiment. It's been clinically proven in Russia that when such peculiarities take place during the process of problem solving, they produce a distorting effect on all cognitive processes and lead to the general deterioration of their productivity, regardless of whether or not the cognitive abilities of participants are high (Zeigarnik, 1972; Kudryavtsev, et al., 1985; Kritskaya, et al., 1991; Nikolayeva, 2011; et al.). The data of correlation analysis display a significant interconnection in frequency between multilevel diversity of thinking phenomena and impulsive answers, both before $(\mathrm{r}=0.784, \mathrm{p}<0.001)$ and after the course of therapy $(\mathrm{r}=0.526, \mathrm{p}<0.01)$. This may indicate that the neuropsychological factor known as the voluntary regulation of mental activity is particularly relevant. Additionally, however, a significant negative correlation was discovered between the frequency of multilevel diversity of thinking phenomena and self-reported data reflecting improvements in health (subjective well-being), after the therapy ( $\mathrm{r}=-0.779, \mathrm{p}<0.001$ ), which punctuate the role of the motivation factor in featuring the aspect of disturbances in thinking (see Appendix, Table 1).

The testing of short-term memory revealed a number of faults: reduced memorization (both verbal and visual memory) and a contraction in what can 
be retained, with memory traces severely inhibited by interfering effects. These are, in terms of pathopsychological interpretation, manifestations of psychoorganic syndrome (chronic brain disorder). A reconciliation of the obtained data with clinical neuropsychology statistics leads to the assertion that the emergence of the described phenomena is mainly caused by an inability of the deep brain structures to function normally (Luria, 1980; Homskaya, 1987; Korsakova \& Moskovichute, 2003; Korsakova \& Varako, 2005). And yet, it is well-known that a deficiency in voluntary regulation and attention, caused by motivation and emotional factors, may feature as very similar aspects of memory disturbances (Zeigarnik, 1972).

Studies of audio-verbal memory discovered that the amount subjects were able to recall, both immediately and following a delay, did not reveal a change at the final examination as compared with the initial check-up. The same may be said for efficiency in memorizing. The number of paraphasia cases, verbal and literal, appeared to significantly decrease. There was also a tendency towards the enhancement of memorizing and a lowering of the number of contaminations. These data are presented in Table 4.

Table 4. Data of parameters of audio-verbal memory disturbances before and after the antihypertensive therapy (percentage of patients that failed to accomplish tests)

\begin{tabular}{lcc}
\hline \multirow{2}{*}{$\begin{array}{c}\text { Parameters of audio-verbal memory distur- } \\
\text { bances }\end{array}$} & Survey $\mathbf{1 , \mathbf { n } = \mathbf { 2 5 }}$ & Survey 2, $\mathbf{n}=\mathbf{2 5}$ \\
\cline { 2 - 3 } & Absolute Value (\%) & Absolute Value (\%) \\
\hline Reduction of immediate recall amount & $12(48 \%)$ & $12(48 \%)$ \\
Reduction of verbatim learning efficiency & $17(68 \%)$ & $12(48 \%)$ \\
Occurrence of contaminations & $4(16 \%)$ & $3(12 \%)$ \\
Reduction of delayed recall amount & $6(24 \%)$ & $6(24 \%)$ \\
Paraphasia cases & $14(56 \%)$ & $8(32 \%)^{*}$ \\
\hline
\end{tabular}

Note. ${ }^{*}$ Differences in values before and after the treatment are significant $(\mathrm{p}<0.05)$.

Before treatment, 22 patients (88\%) had displayed a contracted amount of immediate visual recall, and 3 patients (12\%) had showed low results for delayed recalls. After the course of therapy (which took 24 weeks) the number of patients with the aforementioned disorders diminished to 19 (76\%) and 2 (8\%), respectively.

An analysis of the dynamic parameters of recall process in the "10 words to memorize" method showed that tracings of $72 \%$ of participants had a zigzag shape (see Fig. 1, Patient V.P.), which indicates an instability of mnestic processes. Recall tracings of $16 \%$ of participants revealed a plateau-like shape (see Fig. 1, Patient S.G.), but they displayed no 'edge effect' (Ebbinghaus effect), which may suggest a lack of motivation for memorization. Only 3 patients (12\%) produced tracings that show productive efficiency gains (see Fig. 1, Patient I.I.), though only 2 patients $(8 \%)$ could achieve a maximal result (10 words in five attempts). 
Patient V.P.

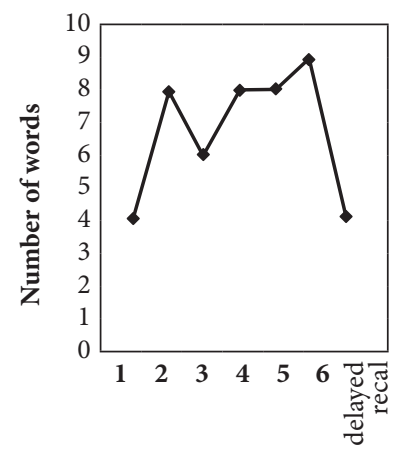

Recall number
Patient S.G.

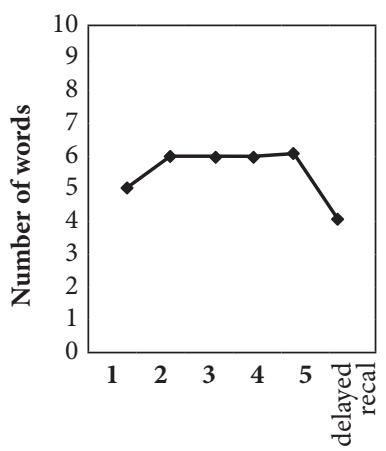

Recall number
Patient I.I.

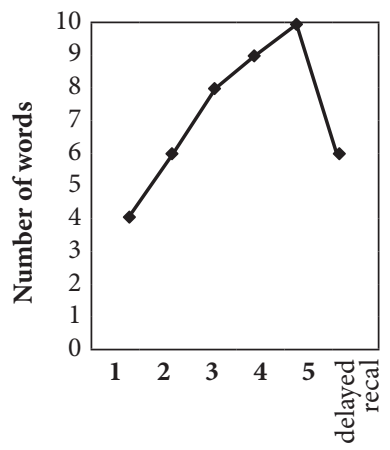

Recall number

Figure 1. Examples of recall tracings of the examined patients with HTN

Re-testing showed an improvement in memorization and high rates for delayed recall (Table 4). It also showed a negative correlation between the verbatim learning efficiency displayed after the therapy and multilevel diversity of thinking before the treatment $(\mathrm{r}=-0.748, \mathrm{p}<0.001)$ (see Appendix, Table 1$)$. This may seem paradoxical, but a more detailed study has brought to light an apparent interconnection: if a participant reveals few (or no) motivation conflicts before treatment, it suggests a more balanced personality structure and emotional sphere, thus, a more spectacular improvement of cognitive functioning can be expected after the therapy. This may prove useful for the prognostication of the cognitive development of HTN patients when therapy is being considered.

Table 5. Data of parameters of mediated memory disturbances before and after the antihypertensive therapy (percentage of patients that failed to accomplish tests)

\begin{tabular}{lcc}
\hline Parameters of mediated memory disturbances & Survey 1, n=25 & Survey 2, n=25 \\
\cline { 2 - 3 } & Absolute Value (\%) & Absolute Value (\%) \\
\hline $\begin{array}{l}\text { Reduction of delayed recall amount } \\
\begin{array}{l}\text { Reduction of recall efficiency for negatively } \\
\text { colored stimuli }\end{array}\end{array}$ & $19(76 \%)$ & $12(48 \%) *$ \\
$\begin{array}{l}\text { Reduction of recall efficiency for neutrally } \\
\text { colored stimuli }\end{array}$ & $8(32 \%)$ & $7(48 \%) *$ \\
$\begin{array}{l}\text { Reduction of recall efficiency for cognitive } \\
\text { complexity stimuli }\end{array}$ & $12(48 \%)$ & $10(40 \%)$ \\
Presence of confabulations & $3(12 \%)$ & $3(12 \%)$ \\
\hline
\end{tabular}

Note. ${ }^{\star}$ Differences in values before and after treatment are significant $(\mathrm{p}<0.05)$.

The pictogram test used to measure mediated memorization showed the following: despite the high percentage of adequate and abstract notions (i.e. correctly revealing their meaning), which patients would choose for mediation in memorizing (which in itself suggests a capacity for high generalizations), they still had difficulties with delayed recall. Only four participants (16\%) replicated the material 
in an amount that was close to norm: they replicated $75 \%$ of it. The difficulties are caused by the fact that mediated activity intensifies the inhibition of memory traces (heterogeneous interference). The relevance of the conclusion is supported by the fact that delayed recall in a "pictogram" test would make a participant recall the entire line of reasoning in the process of image selection, but the very stimulus they would fail to recollect. Within the context of the emotional sphere, an interesting fact emerges: recall efficiency for negatively colored stimuli was twice as low as efficiency for neutrally colored stimuli (Table 5).

There appears to be no direct connection between the lowering of recall efficiency and the cognitive complexity of the stimulus ( $p>0.05)$, though there is a significant negative correlation between the lowering of delayed recall efficiency and the multilevel diversity of thinking phenomena displayed before and after the therapy (see Appendix, Table 1).

Thus, an analysis of the data obtained in the course of the experimental psychological study of cognitive functions in HTN patients was carried out in accordance with the methodological principles of psychological syndrome analysis (VygotskyLuria- Zeigarnik school). It showed the following: within the structure of cognitive disorders, the foreground is gained by disturbances in the dynamic occurrence of mental processes as manifested in general lability, slowing down, and sudden exhaustion caused by a reduction in energy and the neurodynamic provision of mental activity. The conclusion is supported by the high frequency of described symptoms among HTN patients, the low dynamics of their reduction following the anti-hypertensive therapy, and the data of correlation analysis, which relieved a high correlation between the described symptoms and basic indicators of cognitive processes efficiency (see Appendix, Table 1).

The data obtained through the pathopsychological testing of HTN patients demonstrate a significant syndrome-generating role of the dynamic factor in the formation of the syndrome of cognitive disorders. They come in tune with the data obtained through neuropsychological investigations into other groups of HTN patients (Nekrasova, 1987; Korsakova \& Varako, 2005).

However, the data suggest that along with the neurodynamic factor that triggers cognitive dysfunctions in HTN patients, the motivation factor appears to be of no less importance. The performance of experimental tasks makes $30 \%$ of HTN patients reveal to what degree they are motivated. These signs manifest in a lack of motivation for challenging tasks that lay extra demands in terms of psychological activity. The patients did not seem to take pains to succeed, and would not reveal a pronounced reaction to their failure/success. Our study showed that patients with reduced motivation would achieve poor results in general scoring, if compared with a group of highly motivated participants.

As has been noted before, when patients exhibit multilevel diversity in their thinking (as detected in studies on thinking), it often reflects the motivational conflicts they display (Zeigarnik, 1965; Nikolaeva, 2011; et al.). These symptoms are common among the HNT patients surveyed (see Table 3). Correlation analysis data show the interconnection between the frequency of the described phenomena (distortion of the process of generalization and multilevel diversity of thinking) and the frequency in occurrence of various signs of cognitive decline, such as low efficiency in learning, memorization, and delayed recall, as well as low IQ indices (see Ap- 
pendix, Table 1). The data provide a strong argument to support the hypothesis that motivation is of particular importance in the generation of cognitive dysfunctions in HTN patients.

\section{Conclusions}

To sum it up, we consequently applied the methodological principles of psychological syndrome analysis, the procedure of pathopsychological study and patterns of investigation into the pathology of thinking developed by B.V. Zeigarnik to demonstrate that within the syndrome structure of cognitive disorders in HTN patients, the leading part is played by two syndrome-generating factors: neurodynamic and motivational. This verifies the initial hypothesis that motivation was a factor of considerable importance in the formation of cognitive disorders in elderly HTN patients.

The results we obtained have broadened our understanding of the etiology and pathogenesis of hypertension (HTN); they will help health care professionals individualize treatment strategies in medicine and psychology, and pose further questions that will open new perspectives on how to resolve the fundamental issues of psychological science: on "correlation of affect and intellect", on the correlation of objective and subjective determinants of intellectual activity, on the detection of a 'motivation optimum' in problems solving; on the importance of emotional regulation of thinking, etc. We presume that affluence and the multiplicity of original experimental methods and interpreted material, suggested by works of O.K. Tikhomirov and his followers will provide for a solution of outlined tasks (Vasilyev, Popluzhny, Tikhomirov, 1980; Babaeva, et al., 2008; Arestova, 2011; et al.).

The personal meanings theory of thinking advanced by O.K. Tikhomirov is a strikingly evolving conception. His academic studies and those of his followers set high methodological standards of research and have helped enhance psychological practices. This appears to be of paramount importance, given the contemporary state of psychological science, which is commonly inspired by the emergence of new trends and branches, as well as new technologies that provide instruments for studying psychology - all this requires a new comprehension of its methodological grounds and its place among other sciences (Asmolov, 2013; Yurevich \& Ushakov, 2013; Mezzich, 2013; Han, 2009;Zinchenko \& Pervichko, 2013; Zinchenko, Pervichko \& Martynov, 2013).

\section{References}

Arestova, O. N. (2011). Intuitivnoe ponimanie smysla poslovic [Intuitive understanding of the meaning of proverbs]. Voprosy psihologii [Issues in Psychology], 2, 129-138.

Asmolov, A. G.(2013). Strategy and methodology for the sociocultural reform of education. Psychology in Russia: State of the Art, 6(1), 3-20. doi: 10.11621/pir.2013.0101

Babaeva, Yu. D., Berezanskaya, N. B., Vasilyev, I. A., Voiskounsky, A. E., \& Kornilova, T. V. (2008). Smyslovaya teoriya myshleniya [Personal meanings theory of thinking]. Vestnik Moskovskogo universiteta. Seriya 14. Psikhologiya [Moscow University Psychology Bulletin], 2, 26-58. 
Carlson, S. H., \& Wyss, J. M. (2011). Mechanisms Underlying Hypertension and Obesity: A Melanocortin Linkage in the Brain. Hypertension, 57, 375-376. doi: 10.1161/ HYPERTENSIONAHA.110.161729

Cohen, R. A. (2011). Neuroimaging of cardiovascular disease In R. A. Cohen \& L. H. Sweets (Eds.), Brain Imaging in Behavioral Medicine and Clinical Neuroscience (pp. 215-256). New York: Springer. doi: 10.1007/978-1-4419-6373-4

Filimonenko, Y. I., \& Timofeev, V. I. (2001). Test D. Vekslera. Diagnostika struktury intellekta (vzroslyj variant). Metodicheskoe rukovodstvo [D. Wechsler test. Diagnostics of the structure of intelligence (the adult version). Methodical guidance]. St. Petersburg: IMATON.

Graf, P., \& Mandler, G. (1984). Activation makes words more accessible but not necessarily more retrievable. Journal of Verbal Learning and Verbal Behavior, 23 (5), 553-568. doi: 10.1016/ S0022-5371(84)90346-3

Hamer, M., (2010). Adherence to healthy lifestyle in hypertensive patients: ample room for improvement? Journal of Human Hypertension, 24, 559-560. doi:10.1038/jhh.2010.61

Han, S., Fan, Y., Xu, X., Qin, J., Wu, B., Wang, X., Aglioti, S.M., \& Mao, L. (2009). Empathic neural responses to others' pain are modulated by emotional contexts. Human Brain Mapping, 30, 3227-3237. doi: 10.1002/hbm.20742

Homskaya, E.D. (1987). Nejropsihologija [Neuropsychology]. Moscow University Press.

Huppert, F. A., \& Kopellman, M. D. (1989). Rates of forgetting in normal aging: a comparison with dementia. Neuropsychology, 27 (6), 849-860. doi: 10.1016/0028-3932(89)90008-0

Kearney, P. M., Whelton, M., Reynolds, K., Muntner, P., Whelton, P. K., \& He, J. (2005). Global burden of hypertension: analysis of worldwide data. Lancet, 365, 217-223. doi: 10.1016/ S0140-6736(05)17741-1

Kilander, 1., Nyman, H., Boberg, M., Hansson, L., \& Lithell, H. (1998). Hypertension is related to cognitive impairment: a 20-year follow-up of 999 men. Hypertension, 31 (3), 780-786. doi: 10.1161/01.HYP.31.3.780

Kiyaschenko, N. K. (1973). Narushenija pamjati pri lokal'nyh porazhenijah mozga [Memory disorders in patients with local brain lesions]. Moscow University Press.

Korsakova, N. K., \& Varako, N. A. (2005). On determinants of neurocognitive disorders formation in elderly patients with arterial hypertension. Vestnik Moskovskogo Universiteta. serija 14: Psikhologiya [Moscow University Psychology Bulltin], 4, 16-23.

Korsakova, N. K., \& Moskovichute, L. I. (2003). Klinicheskaja nejropsihologija [Clinical neyropsiholgy]. Moscow: Publishing Center "Academy".

Kritskaya, V. P., Meleshko, T. K., \& Polyakov, Yu. F. (1991). Patologija psihicheskoj dejatel'nosti pri shizofrenii: motivacija, obshhenie, poznanie [Pathology of psychic activity in schizophrenia: motivation, communication, cognition]. Moscow University Press.

Krzesinski, J., \& Leeman, M. (2011). Practical issues in medication compliance in hypertensive patients. Research Reports in Clinical Cardiology, 2, 63-70. doi: http://dx.doi.org/10.2147/ RRCC.S12671

Kudryavtsev, I. A., Lavrynovych, A. N., Moskalenko, E. P., \& Safuanov, F. S. (1985). Osobennosti patopsihologicheskoj kvalifikacii rezul'tatov jeksperimental'no-psihologicheskogo issledovanija $v$ uslovijah sudebno-psihiatricheskoj jekspertizy: Metodicheskie rekomendacii [Peculiarities of pathopsychological qualification of the results of experimental psychological investigation under forensic psychiatric examination conditions: Guideline]. Moscow: Publ. of the Institute of Social and Forensic Psychiatry named after VP Serbsky.

Leont'ev, A. N. (1978). Activity, consciousness, and personality. Englewood Cliffs: Prentice Hall.

Luria, A. R. (1980). Higher Cortical Functions in Man. New York: Basic Books. doi: 10.1007/9781-4615-8579-4 
Mezzich J. E., Zinchenko Y. P., Krasnov V. N., Pervichko E. I., \& Kulygina M. A. (2013). Person-centered approaches in medicine: clinical tasks, psychological paradigms, and postnonclassic perspective. Psychology in Russia: State of the Art, 6(1), 95-109. doi: 10.11621/ pir.2013.0109

Nekrasova, E. M. (1987). Osobennosti poznavatel'noj dejatel'nosti i jemocional'no-lichnostnoj sfery $u$ bol'ny arterial'noj gipertenziej pri rannih i obratimy formah narushenij mozgovogo krovoobrashhenija [Features of cognitive activity and emotional personal sphere in hypertensive patients with early and reversible forms of cerebrovascular disturbances] (Doctoral dissertation). Moscow.

Nikolayeva, V. V. (2011). B. W. Zeigarnik and Pathopsychology. Psychology in Russia: State of the Art, 4, 176-192. doi: 10.11621/pir.2011.0010

Pöppel, E., \& Wagner, B. (2012). Von Natur aus kreativ [By nature creative]. München: HanserVerlag, 2012. doi: 10.3139/9783446432864

Rubinstein, S. Ya. (1970). Jeksperimental'nye metodiki patopsihologii i opyt primenenija ih v klinike (prakticheskoe rukovodstvo) [Experimental methods of abnormal psychology and experience of their application in clinic (practice guidelines)]. Moscow: Medicine Publ.

Souetre E. J., Qing W., \& Vigoureux I. (1995). Economic analysis of Alzheimer s disease in outpatients: impact of symptom severity. International Psychogeriatrics, 7, 115-122. doi: 10.1017/ S1041610295001906

Tikhomirov, O.K. (1984). Psikhologiya myshleniya. [Psychology of thinking]. Moscow University Press.

Vasilyev, I. A., Popluzhny, V. L., \& Tikhomirov, O. K. (1980) Emotsii i myshlenie [Emotions and Thinking]. Moscow University Press.

Vygotsky, L. S. (1993b). The diagnostics of development and the pedological clinic for difficult children. In R. W. Rieber \& A. S. Carton (Eds.), The collected works of L. S. Vygotsky: The fundamentals of defectology (abnormal psychology and learning disabilities), 2, 241-291. New York: Plenum Press. doi: 10.1007/978-1-4615-2806-7

Wechsler, D. (1955). Manual for the Wechsler Adult Intelligence Scale. New York: The Psychological Corporation.

Yurevich, A.V., \& Ushakov, D.V. (2013).The Psychological dynamics of modern Russian society: an expert estimate. Psychology in Russia: State of the Art, 6(1), 21-34. doi: 10.11621/ pir.2013.0102

Zeigarnik, B. V. (1965). The pathology of thinking. New York: Consultants Bureau Enterprises.

Zeigarnik, B. V. (1972). Experimental Abnormal Psychology. New York: Plenum Press. doi: 10.1007/978-1-4684-7421-3

Zinchenko Y. P., \& Pervichko E. I. (2013). Nonclassical and Postnonclassical epistemology in Lev Vygotsky's cultural-historical approach to clinical psychology. Psychology in Russia: State of the Art, 6(1), 43-56. doi: 10.11621/pir.2013.0104

Zinchenko Y. P., Pervichko, E. I., \& Martynov, A. I. (2013). Psychological underpinning of personalized approaches in modern medicine: syndrome analysis of mitral valve prolapsed patients. Psychology in Russia: State of the Art, 6 (2), 89-102. doi: 10.11621/pir.2013.0208 